\title{
Os desafios da construção do desenvolvimento no Estado do Rio de Janeiro
}

\author{
José Luis Vianna da Cruz ${ }^{1}$
}

\begin{abstract}
RESUMO
O ERJ vem retomando a dinâmica econômica a partir de atividades que promovem mudanças na sua composição setorial e espacial. Segmentos da indústria de transformação vêm se instalando no interior, acarretando uma efetiva desconcentração espacial. Permanece, no entanto, a dependência da economia estadual em relação ao setor petrolífero. Mais recentemente, um conjunto de investimentos promete impactos ainda mais profundos no território estadual. Investimentos na petroquímica, na indústria naval, na siderurgia, mas sobretudo na infraestrutura de circulação de mercadorias. São portos e terminais portuários espalhados por todo o estado, com destaque para o do Açu, ao norte. A análise das potencialidades de desenvolvimento contidas nesse processo deve ocorrer no âmbito dos vínculos com o padrão brasileiro de inserção na economia internacional, bem como no da incorporação dos indicadores da sua herança socioeconômica. Esse enfoque é ilustrado com a análise do caso do Norte e Leste do estado.
\end{abstract}

Palavras-chave: Estado do Rio de Janeiro; inserção na economia internacional; novas configurações espaciais

\begin{abstract}
ERJ is regaining momentum from economic activities that promote changes in its sectoral and spatial composition. Segments of the manufacturing industry are being settled in the hinterland, causing an effective spatial deconcentration. There remains, however, dependence of the state economy on oil industry. More recently, a number of investments promise even deeper impacts over the territory. Investments in petrochemical, shipbuilding industry, steel industry, but especially in goods transportation infrastructure. Ports and port terminals are located throughout the state, especially the Açu, in the north. The analysis of the development potential contained in this process must occur in links with the Brazilian insertion pattern in the international economy, as well as the incorporation of data in its socioeconomic inheritance. This approach is supported by the analysis of state northern and eastern case.
\end{abstract}

Keywords: Rio de Janeiro State; insertion in the international economy; New spatial framing

\footnotetext{
${ }^{1}$ Doutor em Planejamento Urbano e Regional, pela Universidade Federal do Rio de Janeiro - UFRJ. Professor Associado 2, da Universidade Federal Fluminense-UFF. Professor Colaborador do Mestrado em Planejamento Regional e Gestão de Cidades, da Universidade Candido Mendes-UCAM. joseluisvianna@uol.com.br
} 


\section{Introdução}

O Estado do Rio de Janeiro (ERJ) vem retomando o protagonismo no quadro do crescimento recente da economia brasileira, no campo dos grandes eventos, das obras do Programa de Aceleração do Crescimento $(\mathrm{PAC})^{2}$ do governo federal, dos projetos de exploração do petróleo do Pré-Sal e de importantes investimentos em infraestrutura, principalmente em logística, e na indústria, em segmentos estratégicos do novo perfil de inserção econômica internacional do país.

A retomada vem produzindo profundas mudanças na espacialidade da economia fluminense, em que se destacam a relativa desconcentração das atividades econômicas, tanto no interior da Região Metropolitana do Rio de Janeiro (RMRJ) quanto no interior fora da RMRJ. Desde os sinais de inflexão na dinâmica econômica estadual, na segunda metade dos anos 1990, pesquisadores, com crescente estímulo do fomento da agência estadual de apoio à pesquisa, vêm debatendo o processo, buscando compreendê-lo em sua profundidade e complexidade.

Os resultados, até o momento, apontam no sentido do reconhecimento da importância do processo em curso, acrescentam evidências de que se deve evitar qualquer manifestação de euforia, dada a composição dos indicadores que ilustram o processo, e alertam para a necessidade de incorporação no debate de determinados fenômenos que tomam forma e refletem a natureza do padrão que se vem conformando.

Ao mesmo tempo, reforça-se o sentimento de que, mais uma vez, a discussão sobre o destino do ERJ está atrelada à discussão sobre o destino do Brasil. Este artigo apresenta alguns indicadores dos rumos que a economia estadual vem tomando e chama a atenção para questões de fundo, vinculando a economia à dimensão social do desenvolvimento, como análise que deve orientar as tomadas de posição e as intervenções de políticas públicas e de ação social no enfrentamento dos desafios de promoção do desenvolvimento à escala estadual.

Este artigo busca colaborar para a compreensão do momento atual da economia fluminense, a partir das seguintes questões: qual o perfil da retomada do crescimento da economia fluminense? Em que contexto deve se situar a análise da composição dos vetores

\footnotetext{
${ }^{2}$ Trata-se do programa federal que abarca os investimentos considerados prioritários pelo governo, e que, por isso mesmo, estão fora do cálculo do superávit primário.
} 
de crescimento? Quais as implicações para o desenvolvimento do ERJ das configurações regionais do atual crescimento? Quais os principais problemas do ERJ que devem ser considerados numa estratégia de desenvolvimento?

Essas questões serão tratadas nas próximas três seções. Primeiramente, são apresentados os principais aspectos que compõem o perfil da retomada do crescimento da economia fluminense e a conformação econômica e espacial desse processo. Em seguida, serão abordados os vínculos entre o padrão que se configura e a dinâmica de inserção internacional da economia brasileira. A seguir serão analisados um conjunto de indicadores que, ao lado da problemática da inserção nacional/internacional da economia fluminense, devem ser incorporados no esforço de compreensão das grandes tendências no rumo da economia do estado.

\section{Para onde aponta a recente dinamização da economia do ERJ?}

A leitura histórica é particularmente importante para entender o momento por que passa o ERJ e os desafios ao seu desenvolvimento socioespacial e sociopolítico, o que remete a dois aspectos fundamentais.

O primeiro é a dimensão institucional da posição e do papel do município do RJ na federação, pela sua importância e longevidade. O Rio foi "capital" da colônia, a partir de 1763; sede de todo o império português, a partir de 1808; sede do império brasileiro, a partir de 1822; capital da república, de 1889 a 1960; município-estado, até 1975, e capital de estado, até o presente. Para além do status, essa trajetória político-administrativa de exatos 250 anos - como centro do poder na colônia, no império e na república; como cidade-estado e capital estadual, além de sede de região metropolitana - construiu um complexo de relações e práticas sociais, políticas, econômicas e culturais - com o correspondente arcabouço simbólico de autorrepresentação e de imagem "para fora" decisivo para a compreensão da configuração espacial da economia do atual ERJ.

O Rio-Capital e, mais tarde, o Rio-Município (RJ-M), engendrou uma região metropolitana que se consolidou, inicialmente, como povoados agrícolas situados nos corredores do minério e de abastecimento das minas gerais e da cidade do Rio de Janeiro, como locais de repouso e reabastecimentos das "tropas" de animais de transporte, área agrícola que teve o café como produto importante até o primeiro quarto do século XX. 
Posteriormente, o entorno do RJ-M abrigou cidades-dormitório para os operários e funcionários públicos da capital, bem como um parque industrial iniciado com indústrias de base e posteriormente diversificado.

O outro aspecto, consequência do primeiro, é o do lugar do interior, sendo o interior compreendido pelos municípios fora da Região Metropolitana do Rio de Janeiro (RMRJ), ou do recorte interior-capital, na compreensão da estrutura e da dinâmica espaciais da socioeconomia do estado. Ao mesmo tempo em que se constata uma importante defasagem histórica entre o dinamismo do interior e da capital, pode-se também reconhecer a dominância dos estudos carioca-centrados, até pouco tempo, em que o interior aparecia, em grande parte, como apêndice do estado, o que é perfeitamente compreensível em decorrência da centralidade da metrópole, particularmente do elevado grau de concentração das atividades de formação, estudos e pesquisas e dos seus portavozes (Cruz, 2013).

A implantação da economia do petróleo e, mais recentemente, a retomada do crescimento pela indústria, no estado, ao lado da crescente desconcentração das atividades de formação, estudos e pesquisas, vêm relativizando um certo olhar marcado por uma visão "etnocêntrica" dos estudos realizados na capital e por intelectuais da capital. O interior, aos poucos, ocupa lugar no palco, tanto na economia quanto na reflexão e na produção acadêmica sobre si próprio, sobre o estado e sobre a capital, com a contribuição de estudiosos do interior, que produzem a partir do interior e que vivem e trabalham no interior do estado.

Os declínios dos ciclos do café (na primeira metade do século XX) e da cana-deaçúcar (na segunda metade do século XX) ocorreram concomitantes ao declínio da indústria fluminense, até recentemente, o que, aliados ao desmonte da burocracia políticoadministrativa, explicam, em grande parte, o esvaziamento econômico relativo do ERJ, até meados dos anos 1990, ao mesmo tempo em que passava a ancorar seu dinamismo na economia petrolífera (Natal, 2007). No período de crise, houve fechamento - inclusive da Bolsa de Valores - e transferência de indústria e sedes de empresas, neste último caso para São Paulo, principalmente.

Segundo Silva (2008), quando se exclui o petróleo, constata-se o declínio da posição relativa do ERJ na produção industrial nacional, nesse período, até mesmo em relação ao Estado do Espírito Santo, em termos do Vetor Densidade Industrial (VDI). 
Discute-se se teria havido esvaziamento econômico, em termos gerais, desindustrialização ou inflexão nos componentes da base econômica, com o deslocamento de setores, ramos e segmentos da economia estadual tradicional pela economia do petróleo, em detrimento de alguns segmentos industriais (Silva, 2008). ${ }^{3}$

A retomada vem sendo sustentada, apesar da reestruturação de alguns segmentos e da implantação de novos, pela economia do petróleo, tanto pelos aspectos produtivos quanto pelas rendas petrolíferas, após a Lei do Petróleo, de 1997. Mais recentemente, a partir do início do século XXI, outros segmentos da indústria de transformação elevam seu peso na dinamização da economia estadual, como o segmento metal-mecânico e de transporte.

A capital mantém sua vocação para os serviços, a indústria se desconcentra um pouco na RMRJ, mas é o interior que mais cresce, com novos espaços regionais sendo incorporados à dinâmica econômica estadual. Surgem novos e importantes investimentos em logística, infraestrutura, petroquímica, indústria automobilística, indústria de softwares, e outros.

O importante é assinalar que há uma dependência da economia fluminense em relação ao setor de petróleo e gás, compreendendo exploração, produção, refino, petroquímica e gás-química. Territorialmente, o segmento de exploração e produção de petróleo e gás (E\&P) está concentrado no Norte Fluminense (NF), mais precisamente em Macaé, e se expande pela Região das Baixadas Litorâneas.

O período de reestruturação produtiva do Brasil pós-crise dos anos 1980, cujos resultados se tornam visíveis nos anos 1990 - com a radicalização da privatização dos serviços públicos e de empresas estatais, a maturação do ajuste fiscal e o desfecho da crise da dívida e do enfrentamento da inflação, entre outras medidas -, produziu um novo perfil de inserção do ERJ na economia brasileira, culminando com a retomada recente dos investimentos (Oliveira, 2008; Silva, 2012).

O ERJ passa por um ciclo de industrialização e de crescimento da infraestrutura econômica vinculados ao perfil de retomada do crescimento brasileiro, que tem sua ênfase na exportação de commodities agrícolas e minerais, apoiado na exploração dos recursos

\footnotetext{
${ }^{3}$ Segundo Silva (2008), o VDI varia entre zero e um e define a posição relativa dos estados em termos de sua densidade industrial. Pode ser entendido como um índice de competitividade da indústria em termos de uma região, de estado. Densidade Industrial significa estrutura produtiva articulada, diversificada, autossustentável, com elevado nível de produtividade, competitiva no plano internacional, entre outras características.
} 
naturais, na produção agroindustrial de alimentos e em produtos industriais semiacabados; e na indústria de transformação, na siderúrgica, naval, automotiva e petroquímica. No estado os investimentos ocorrem em infraestrutura portuária, rodoviária, ferroviária e aeroviária; na infraestrutura urbana ligada ao Programa de Aceleração do Crescimento (PAC) e aos grandes eventos, estes últimos concentrados na Região Metropolitana do RJ.

No estado os investimentos em infraestrutura se dão, principalmente, no âmbito do PAC do governo federal; dos projetos de exploração do petróleo da camada do Pré-Sal; e da preparação do RJ-M para os grandes eventos internacionais. São viabilizados em parcerias com o BNDES, governo do Estado e governos de municípios privilegiados com rendas extras, como as rendas petrolíferas. E são incluídos como investimentos estratégicos nos programas de investimento em logística, do governo federal, em ferrovias e rodovias, portos e terminais, e aeroportos, em parcerias público-privadas.

No ERJ estão previstos e em curso investimentos em portos e terminais portuários, minerodutos, centros de armazenagem e estocagem e de "limpeza" do petróleo, ferrovias, rodovias e corredor logístico. Na indústria, em termelétricas, siderúrgicas, petroquímica, cimenteiras, montadoras, entre outras. Os investimentos estaduais estão vinculados, mais diretamente, a minério de ferro, petróleo e gás, produção de energia, combustível, aço, navios.

São previstos grandes impactos na configuração socioespacial do estado. $\mathrm{O}$ atual processo mobiliza e "integra", des-estrutura e des-integra, áreas, municípios, micro e mesorregiões. Os investimentos vultosos em atividades industriais, portuárias e de logística de armazenagem e circulação de mercadorias atravessam o ERJ de Norte a Sul, incorporando áreas antes periféricas e excluídas, penalizadas nos ciclos dinâmicos anteriores, borrando as fronteiras territoriais e transformando as dinâmicas econômicas existentes, particularmente no litoral e no eixo rodoviário da BR-101 (Cruz, 2012).

Em síntese, pesquisas recentes sobre a retomada do crescimento econômico do estado (Oliveira, 2008; Silva, 2012) revelam que: 1) é protagonizado pela indústria, com hegemonia do segmento extrativista de petróleo \& gás; 2) configura-se como um processo de relativa, mas significativa, desconcentração espacial, distribuindo-se por grande parte do território do interior do estado fora da RMRJ, contemplando diversas regiões; 3) os investimentos no interior superam aqueles que ocorrem na sede, em ritmo e valores, 
embora a capital mantenha a concentração no setor de serviços e a RMRJ sedie uma industrialização diversificada.

A Tabela 1, a seguir, desmembra os investimentos por setor de atividade.

Tabela 1. Investimentos por setor de atividade

\begin{tabular}{|c|c|c|}
\hline Setor & $\begin{array}{c}\text { Valor do investimento no } \\
\text { período 2012-2014 (R\$ bilhões) }\end{array}$ & $\%$ \\
\hline Instalações olímpicas & 8,6 & 4,1 \\
\hline Indústria de transformação & 40,5 & 19,2 \\
\hline Infraestrutura & 51,0 & 24,1 \\
\hline Petrobrás & 107,7 & 50,9 \\
\hline Turismo & 1,8 & 0,8 \\
\hline Outros & 1,9 & 0,9 \\
\hline Total & 211,5 & 100,0 \\
\hline
\end{tabular}

Fonte: Firjan (2012). Decisão Rio 2012-2014, p. 13.

http://www.firjan.org.br/decisaoport2012-2014/files/decisaorio2012-2014_pt.pdf

Percebe-se, pela Tabela 1, que o segmento de petróleo \& gás, representado pela Petrobras, representa, individualmente, o maior investimento, seguido de infraestrutura, que será melhor especificado adiante, e de transformação, onde cerca de metade corresponde ao Complexo Petroquímico do Rio de Janeiro (COMPERJ). Trata-se, portanto, de investimentos concentrados, em termos setoriais e em poucos segmentos e unidades desses setores, o que leva à concentração espacial dos setores e segmentos, embora esses contemplem novos espaços e reforcem a desconcentração relativa, como nos casos da petroquímica, da automotiva e da naval. Em particular, chama atenção o investimento nas instalações olímpicas, também concentrado na capital. É na infraestrutura, em geral, que a espacialidade fica mais dispersa. 


\section{Figura 1. Regiões de Governo do Estado do Rio de Janeiro}

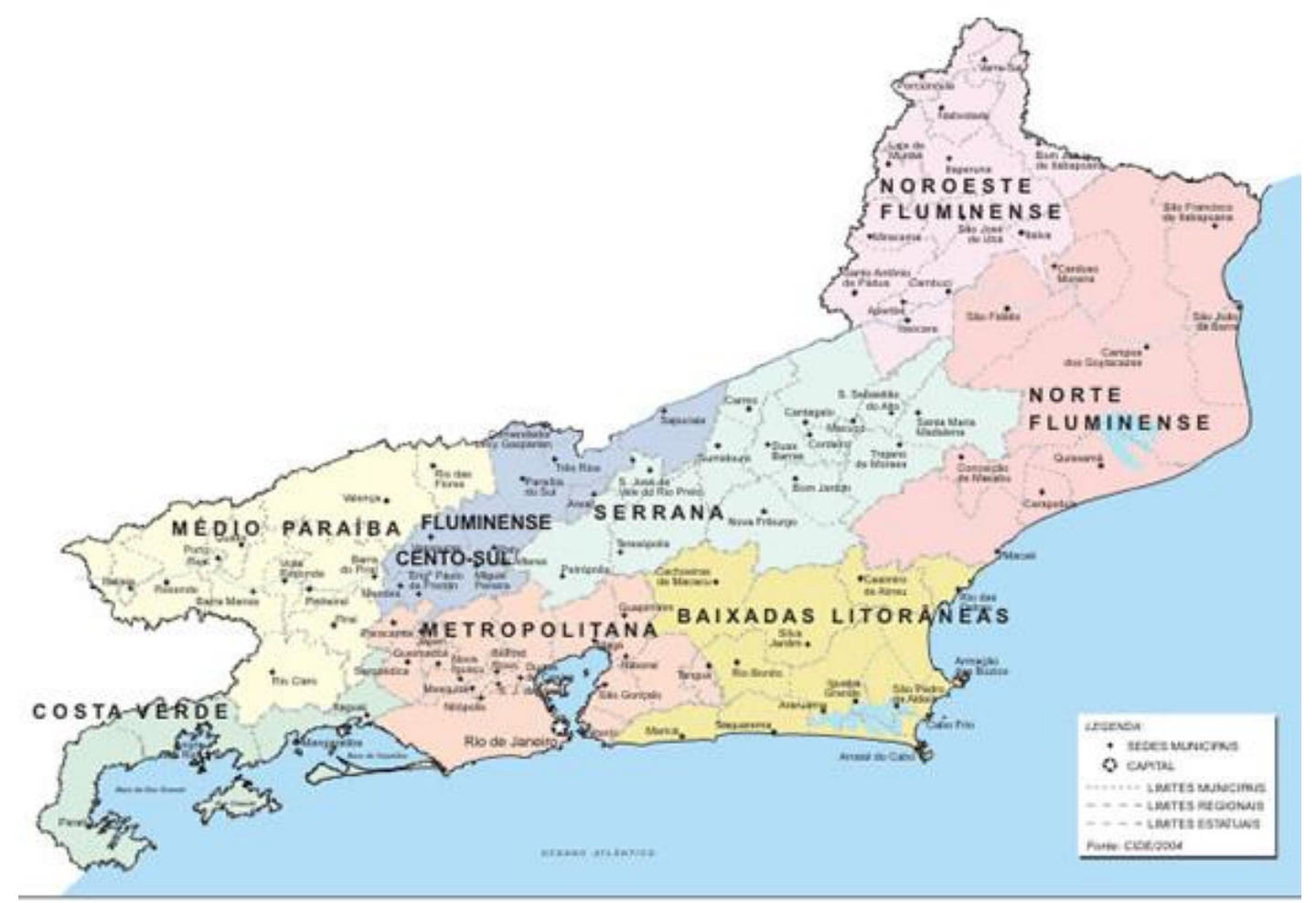

Fonte: www.codin.rj.gov.br

Quando se observam os investimentos na indústria de transformação (Tabela 2) e a distribuição regional do conjunto dos investimentos (Tabela 3), percebe-se a tendência à relativa desconcentração espacial, em relação ao município e à Região Metropolitana do RJ e os sinais de uma especialização em alguns segmentos: 1) metal-mecânico e automotivo no Médio Paraíba, Centro-Sul e Região Metropolitana; 2) químico e petroquímico, na Região Metropolitana; 3) de exploração e produção de petróleo e gás $(\mathrm{E} \& \mathrm{P})$, no Norte e Leste (a delimitação de uma região denominada Leste é utilizada pela Federação das Indústrias do Estado do Rio de Janeiro (Firjan) para pontuar o espaço de influência direta do COMPERJ, que abarca municípios da RMRJ e municípios da Baixada Litorânea (BL), fundindo-se aos impactos que vêm do complexo de E\&P, do Norte); 4) da construção naval e infraestrutura portuária na Região Metropolitana, na Costa Verde, e no Norte Fluminense, embora com terminais ao longo de toda a costa; e 5) siderúrgico, que tende a se espalhar, com novas unidades próximas a terminais de minério, como no Norte.

As tabelas a seguir têm como fonte a Firjan, por isso a referência territorial são as representações regionais (RR). Para os objetivos deste artigo, considera-se válida essa base 
espacial na medida em que o que se quer destacar são os aglomerados territoriais dos investimentos que vêm se formando, que, embora utilizem a referência das regiões de governo, não se atêm às mesmas.

A espacialidade dos investimentos segundo a base territorial das RRs corresponde, em termos gerais, à das regiões de governo, com algumas inclusões e exclusões de municípios que não comprometem a mancha espacial da influência desses investimentos. Os territórios dos investimentos mais importantes do ERJ, segundo a Tabela 3, portanto, compreendem as regiões da Sede, do Norte, do Sul, da Baixada I, da Leste e da Baixada II.

Correspondem, considerando-se a divisão das regiões de governo, com as ressalvas já destacadas, à mancha espacial que vai do Norte Fluminense e Baixadas Litorâneas (região da economia extrativista petrolífera e logística portuária, com potencial na indústria naval), segue pela RMRJ (região do complexo petroquímico, de diversificação industrial, de logística portuária, da indústria naval e de serviços), envolve o Médio Paraíba e parte do Centro-Sul (região do polo metal-mecânico, siderúrgico, de transporte) e chega à Costa Verde (região de logística portuária, com potencial de siderurgia e indústria naval).

Tabela 2. Investimentos previstos na indústria de transformação fluminense

\begin{tabular}{lcc}
\hline Setor & $\begin{array}{c}\text { Valor do investimento no período } \\
\text { 2012-2014 (R\$ bilhões) }\end{array}$ & $\%$ \\
\hline Construção Naval & 15,4 & 38,0 \\
Siderurgía & 10,1 & $\mathbf{2 4 , 8}$ \\
Petroquímico & 6,1 & $\mathbf{1 5 , 1}$ \\
Automotivo & 6,1 & $\mathbf{1 5 , 1}$ \\
Outros & 2,8 & $\mathbf{7 , 0}$ \\
\hline Total & $\mathbf{4 0 , 5}$ & $\mathbf{1 0 0 , 0}$ \\
\hline
\end{tabular}

Fonte: Firjan (2012). Decisão Rio 2012-2014, p. 17.

http://www.firjan.org.br/decisaoport2012-2014/files/decisaorio2012-2014_pt.pdf 
Tabela 3. Investimentos previstos por região do estado

\begin{tabular}{lcc}
\hline Região & $\begin{array}{c}\text { Valor do investimento no } \\
\text { período 2012-2014 (R\$ bilhões) }\end{array}$ & $\%$ \\
\hline Sede - Município do Rio de Janeiro & 34,5 & 16,3 \\
Região Norte Fluminense & 26,0 & 12,3 \\
Região Sul Fluminense & 14,1 & 6,7 \\
Região Baixada Fluminense - Área I & 11,9 & 5,6 \\
Região Leste Fluminense & 11,4 & 5,4 \\
Região Baixada Fluminense - Área II & 2,7 & 1,3 \\
Região Noroeste Fluminense & 0,8 & 0,4 \\
Região Serrana & 0,5 & 0,2 \\
Região Centro Norte Fluminense & 0,5 & 0,2 \\
Várias* & 109,1 & 51,6 \\
\hline Total geral & 211,5 & 100,0 \\
\hline Interior inclusive Baixadas & $\mathbf{6 7 , 9}$ & \\
\hline Rio-M & $\mathbf{3 4 , 5}$ & \\
\hline Baixada I + II & $\mathbf{1 4 , 6}$ & \\
\hline Interior s/ Baixadas & $\mathbf{5 3 , 3}$ & \\
\hline
\end{tabular}

Fonte: Firjan (2012). Decisão Rio 2012-2014, p. 20.

http://www.firjan.org.br/decisaoport2012-2014/files/decisaorio2012-2014_pt.pdf

*Investimentos que não se restringem a uma única região, a exemplo de obras em rodovias e investimentos da Petrobras.

ATabela 3 permite alguns destaques importantes. Excluindo-se o item "várias", por não ser regionalizado: 1) o interior fora capital e da Região Metropolitana (Baixadas I e II) responde por mais de $50 \%$ do volume total dos investimentos; 2) somando-se às baixadas (RMRJ) o interior fora capital representa quase $70 \%$ do total; 3) em seguida vem a capital, com mais do dobro dos investimentos dos municípios da Região Metropolitana.

Além dos investimentos industriais, em capital fixo, outra classe de investimentos constitui vetor de grandes impactos territoriais, e ocorre no terreno dos fluxos. Trata-se dos investimentos em infraestrutura, como suporte, não só aos investimentos produtivos de capital fixo no território estadual, mas também aos investimentos produtivos nacionais.

Constituem investimentos de infraestrutura de suporte físico à circulação de mercadorias, vinculados, principalmente, ao comércio exterior, que vão intensificar o uso do território do ERJ - num continuum territorial com o Espítrito Santo, onde haverá um porto em Presidente Kenendy, no Sul, e um terminal em Anchieta, no Centro-Sul - como plataforma territorial nacional de corredores de exportação e importação. Entre os 
investimentos em infraestrutura, ainda, encontram-se aqueles vinculados ao PAC, que têm grande peso na infraestrutura urbana, e aos grandes eventos no município do Rio de Janeiro. A Tabela 4 apresenta uma desagregação dos investimentos em infraestrutura.

Tabela 4. Investimentos previstos em infraestrutura no Rio de Janeiro

\begin{tabular}{lcc}
\hline Setor & $\begin{array}{c}\text { Valor do investimento no } \\
\text { período 2012-2014 (R\$ } \\
\text { bilhões) }\end{array}$ & $\%$ \\
\hline Saneamento básico & 4,3 & $\mathbf{8 , 5}$ \\
Desenvolvimento urbano & 10,6 & $\mathbf{2 0 , 8}$ \\
Energia & 14,8 & $\mathbf{2 8 , 9}$ \\
Transporte/Logística & 21,3 & $\mathbf{4 1 , 8}$ \\
\hline Total & 51,0 & 100,0 \\
\hline
\end{tabular}

Fonte: Firjan (2012). Decisão Rio 2012-2014, p. 17.

http://www.firjan.org.br/decisaoport2012-2014/files/decisaorio2012-2014_pt.pdf

Como se pode observar na Tabela 4, os investimentos em transporte/logística são os mais significativos, seguidos dos direcionados à produção de energia, que é um insumo essencial às atividades econômicas, e mais distante, os vinculados ao saneamento básico. Adiante, a Figura 2 permite visualizar a rede estadual correspondente às expectativas de demanda que o incremento de circulação de mercadorias deverá gerar, correspondente às intervenções portuárias e à consolidação do espaço fluminense como espaço de fluxo internacional de mercadorias.

O mapa dessa rede, na Figura 2 (Firjan, 2011), a seguir, torna mais nítidas suas conexões com a estratégia exportadora da retomada do crescimento brasileiro e o lugar que se quer reservar ao Rio de Janeiro nessa estratégia. Como se vê, para além do Arco Rodoviário Fluminense, há previsões de conexões rodoviárias e ferroviárias com as áreas do Centro-Oeste e Norte do país, constituindo novos corredores de escoamento para o litoral da produção agropecuária e mineral dessas regiões, desembocando em cerca de uma dezena de portos e terminais previstos e em construção, no estado. 
Figura 2. Plataforma Logística Fluminense

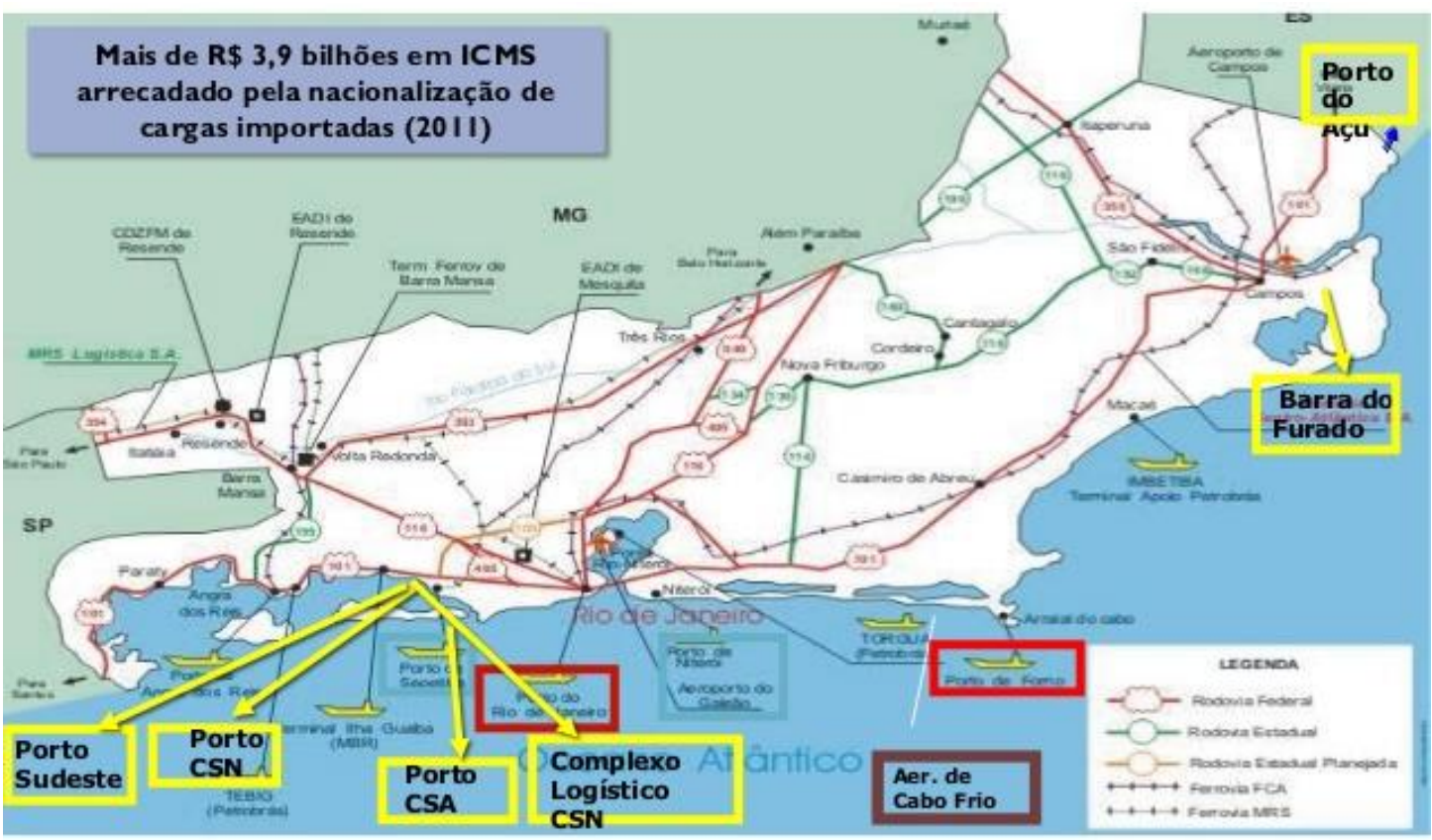

Fonte: Secretaria de Transporte do Rio de Janeiro. Acessado em:

http://www.slideshare.net/alerj/secretaria-de-transportes-secretaria-de-transportes-rio-de-janeiro020413-logstica-e-infraestrutura-para-a-competitividade-alerj-frum-de-desenvolvimento

A Figura 2, ao apontar os investimentos demandados e previstos para equacionamento da logística de transporte de cargas no ERJ, oferece uma panorâmica da extensão, da complexidade e da densidade da malha, prevendo-se impactos espalhados por todo o território estadual. As vias são traçadas pelas empresas, ligando, da forma mais racional possível, em termos de produtividade e rentabilidade, os pontos que mais favorecem os interesses corporativos dos envolvidos nos negócios.

Enquanto corredores de escoamento da produção vinculada ao comércio internacional, ao mesmo tempo em que não são orientados por objetivos de integração territorial nos interstícios entre a origem e o destino das mercadorias, possuem grande potencial de impactos ambientais. É bom lembrar que o futuro litoral dos portos é o tradicional litoral do turismo e lazer. Como os portos e terminais necessitam isolar uma área do oceano, de aproximação de embarcações, pode-se estimar impactos capazes de afetar esse segmento econômico.

A Tabela 5, a seguir, desagrega os investimentos vinculados aos dois principais eventos dos próximos quatro anos. Os dois segmentos somados receberão investimentos 
superiores ao de qualquer um, considerado individualmente, do setor da indústria de transformação, conforme apresentado na Tabela 2.

Tabela 5. Investimentos relacionados à Copa do Mundo e aos Jogos Olímpicos

\begin{tabular}{lc}
\hline Segmentos & $\begin{array}{c}\text { Valor do investimento no período } \\
\text { 2012-2014 (R\$ bilhões) }\end{array}$ \\
\hline Infraestrutura de transporte* & 7,7 \\
Rede hoteleira e outros investimentos turísticos & 1,6 \\
$\begin{array}{l}\text { Investimentos do Comitê Olímpico (ainda não } \\
\text { detalhados) }\end{array}$ & 2,5 \\
$\begin{array}{l}\text { Demais investimentos públicos e privados na } \\
\text { organização dos Jogos (ainda não detalhados) }\end{array}$ & 6,1 \\
\hline Total & 17,9 \\
\hline
\end{tabular}

Fonte: Firjan (2012). Decisão Rio 2012-2014, p. 17.

http://www.firjan.org.br/decisaoport2012-2014/files/decisaorio2012-2014_pt.pdf .

* Inclui as obras de construção do metrô, linha 4, implantação do sistema de BRTs, e modernização do aeroporto internacional Galeão - Tom Jobim.

Em suma, as configurações espaciais desses impactos sofrerão influência tanto da implantação física dos equipamentos industriais, localizados, fixos, quanto das vias voltadas para o fluxo de mercadorias originárias de outras regiões do país, que atravessarão todo o território e desembocarão nos diversos portos e terminais ao longo do litoral estadual.

Uma das tendências decorrentes e que se manifesta concretamente é a da formação de um continuum territorial, ao longo de todo o litoral do estado, praticamente sem interrupções, incorporando toda a RMRJ e alcançando, no interior, parte do Centro-Sul e do Médio Paraíba.

São esses os principais vetores de definição das condições do desenvolvimento fluminense para os próximos anos: investimentos industriais, de logística e infraestrutura que atrelam os usos e funções do território à estratégia internacional da economia brasileira, apropriando-se, e em determinadas situações, sequestrando os recursos construídos ao longo da sua história. Não se pode desvincular esta análise do exame da herança produtiva, social e urbana do estado, como condição para avaliar as perspectivas que esse processo encerra para o seu desenvolvimento.

A título de demonstração deste procedimento analítico, apresentam-se, a seguir, as evidências que já são palpáveis no caso do território da economia do petróleo, que - a 
partir da retomada do crescimento da economia brasileira, da elevação da importância da produção de petróleo e gás nessa matriz, da expansão dos segmentos de exploração \& produção bem como do petroquímico no estado, e sua consequente pressão sobre a infraestrutura de logística - desencadearam um conjunto de investimentos que amplia a sua base territorial regional e torna mais complexa a equação do desenvolvimento regional e urbano do estado.

\subsection{O Norte e o Leste do ERJ como corredor de investimentos}

O Norte Fluminense (NF) vem recebendo um conjunto de importantes e diversificados investimentos, alguns de grande porte, a partir da segunda metade da primeira década deste século, que deverão produzir profundos impactos na economia e na sociedade. As tendências apontam no sentido de um profundo reordenamento do território, no tocante à configuração urbana e às estruturas produtiva e socioeconômica.

A Região das Baixadas Litorâneas (BL) constituía, historicamente, uma região de turismo e lazer, com atividades produtivas voltadas para o abastecimento do Grande Rio, como a agricultura e a indústria cerâmica. Após a implantação do Complexo de E\&P tornou-se também região de moradia de trabalhadores e área de instalação de empresas ligadas ao Complexo, além de ter alguns dos seus municípios contemplados com as rendas petrolíferas milionárias decorrentes das mudanças implantadas pela Lei do Petróleo, de 1997, que extinguiu o monopólio da Petrobras, na exploração do petróleo e elevou enormemente os valores das rendas petrolíferas.

A implantação do COMPERJ, em Itaboraí, prevê intervenções na fronteira com a BL, como o terminal portuário de Maricá. Esse território já se encontrava conurbado, em decorrência do uso histórico para turismo e lazer e das novas funções ligadas ao segmento de petróleo e gás. Suas condições privilegiadas para moradia e lazer deverão atrair, igualmente, segmentos de trabalhadores das empresas ligadas ao COMPERJ, o que deverá agravar o já acelerado e intenso adensamento urbano.

Alguns aspectos desse fenômeno expressam a relevância do processo em curso: 1) o NF, após longo período de declínio econômico, tornou-se a maior região produtora de petróleo do país e sede de alguns dos municípios mais ricos em termos de rendas petrolíferas; 2) os novos investimentos se inserem num conjunto que se difunde por todo o Estado do Rio de Janeiro, o que, por sua vez, se coaduna com a estratégia recente de 
retomada do crescimento e de inserção do Brasil na economia internacional; e 3) a BL e o denominado Leste compreendem os municípios situados no território de encontro das atividades de extração do petróleo e gás com as atividades de beneficiamento do COMPERJ e de consumo dos moradores da capital, em turismo e lazer, que se funde com a RMRJ, portadora histórica de gravíssimos problemas sociais e urbanos.

A Tabela 6 apresenta alguns números que evidenciam a constituição de novas configurações espaciais no ERJ, aplicadas ao caso do Norte e BL, ou do Leste. O exercício aqui realizado para o Norte e Leste do estado pode ser estendido a todo os segmentos territoriais do estado afetados diretamente pelas atividades que respondem pela dinamização recente da economia estadual e ao território estadual dos novos investimentos.

Percebe-se, pelos dados, o potencial de constituição de uma unidade territorial urbano-regional que compreende o Norte e o projetado Leste, promovendo a conurbação do corredor territorial que vai do município de São João da Barra, sede do Complexo do Açu, até os 11 municípios do CONLESTE, território delimitado como de influência direta dos impactos do COMPERJ, que abarca municípios das Baixadas Litorâneas e da RMRJ. Esta, por sua vez, tende a constituir uma unidade territorial que projeta um continuum com o Médio Paraíba e o Sul Fluminense, ou Costa Verde.

Tabela 6. O espaço urbano-regional do Norte/Leste Fluminense (corredor Petróleo\&Gas + COMPERJ)

\begin{tabular}{|c|c|c|c|}
\hline & $\begin{array}{l}\text { Crescimento Pop. } \\
2000-2010\end{array}$ & $\begin{array}{l}\text { Particip. no PIB } \\
\text { estadual (2008) }\end{array}$ & $\begin{array}{l}\text { Dos } 10 \text { maiores } \\
\text { investimentos }\end{array}$ \\
\hline \multirow{3}{*}{$\begin{array}{l}\text { Posição relativa no } \\
\text { Estado }\end{array}$} & NF: $22 \%$ & NF: $13 \%$ & NF: \\
\hline & $1^{\circ}$ lugar & $2^{\circ}$ lugar & $2^{\circ}, 3^{\circ}, 7^{\circ}$ e $8^{\circ}$ \\
\hline & $\begin{array}{l}\text { Leste: } 22 \% \\
\text { 1 lugar }\end{array}$ & $\begin{array}{l}\text { Leste: } 11,6 \% \\
\text { 4ㅇ lugar }\end{array}$ & $\begin{array}{l}\text { Leste: } \\
1 \stackrel{0}{ }\end{array}$ \\
\hline
\end{tabular}

Fonte: Firjan (2012). Decisão Rio 2012-2014; IBGE, Censo 2010; elaboração própria.

Como se pode ver, na Tabela 6 , as duas regiões apresentam o maior ritmo de crescimento populacional do estado, o $2^{\circ}$ e o $4^{\circ}$ lugares em participação no PIB, sendo que o primeiro lugar nesses dois quesitos pertence à RMRJ. A soma do PIB das duas regiões representa um quarto do total estadual. A região sedia os três maiores investimentos do estado. Dos dez maiores, quatro estão previstos ou em curso nas duas regiões.

Quando se observam os investimentos estaduais por região, previstos para o período 2012-2014 (Tabela 3), percebe-se que, excluindo-se a Sede, ou o RJ-M, o NF é a 
região que receberá o maior volume de investimentos, que, somados aos da Região Leste, representam, juntos, quase um quinto do investimento total do estado, superando o peso dos investimentos na sede.

As previsões para os municípios de Campos e São João da Barra - assumidas pela EBX, holding de várias empresas envolvidas no Complexo do Açu, citando o IBGE como fonte das projeções, e que constitui a referência com que as prefeituras e empresas envolvidas trabalham, constando do Estudo de Impacto Ambiental e seu respectivo Relatório (EIA-RIMA) - é de que nos próximos 15 anos a população conjunta de Campos e São João da Barra passará das atuais quinhentas mil pessoas para um milhão, sendo 750.000 em Campos e o restante em SJB, que crescerá mais, proporcionalmente.

Mesmo considerando-se a recente crise do Grupo EBX, o mineroduto e o terminal de exportação de minério de ferro estão em fase adiantada, permitindo antever sua conclusão e funcionamento efetivos, ainda que sob novos proprietários e/ou operadores. A demanda da exploração do petróleo do pós e do pré-sal permite, igualmente, prever que importantes unidades econômicas e industriais do Complexo do Açu devem ser viabilizadas, mesmo sofrendo atrasos e mudanças das empresas responsáveis. Feitas as devidas correções quantitativas permanecem os vetores de investimentos.

O processo em curso no ERJ deve ser tratado, ainda, em suas conexões com as intervenções no Sul do Estado do Espírito Santo, nos municípios de Presidente Kennedy construção de um terminal de exportação de minérios - e Anchieta, onde está sendo implantada uma siderúrgica e o porto de Ubu. Embora o espaço não permita aprofundar o assunto, deve-se registrar que há previsão de se completar a ligação rodoviária litorânea do ES com o RJ, o que deve gerar novos polos de crescimento urbano e uma nova conurbação litorânea unindo o Centro-Sul do ES ao Rio de Janeiro, passando pelo NF. Para efeito deste artigo, no entanto, o recorte se restringirá ao NF e ao Leste do ERJ, como base para as argumentações.

Como já foi dito, os investimentos em curso no Rio de Janeiro situam-se no conjunto dos grandes investimentos que se espalham por todo o território brasileiro, e fazem parte de um grande portfolio que tem como invólucros o PAC, o Pós e o Pré-Sal, o Plano Energético Nacional, o Programa de Investimentos em Logística: Rodovias e Ferrovias, a MP dos Portos, a estratégia do BNDES de construir "protagonistas globais" ou "global players", a realização de grandes eventos internacionais, e os programas e ações de 
sustentação e ampliação da produção e exportação de commodities minerais, agropecuárias e agroindustriais, e de segmentos de bens industriais intermediários e semiindustrializados.

\section{Vínculos da retomada com o padrão de inserção internacional da economia brasileira: impactos e impasses}

A literatura acadêmica tem enfatizado o perfil que vem se consolidando na economia brasileira após a retomada recente do crescimento econômico, a partir dos dois governos do presidente Lula, 2002-2010. Desde o Governo Collor, no início da década de 90 do século XX, passando pelos dois governos de Fernando Henrique Cardoso (19952002), as medidas de ajuste fiscal e as contrapartidas econômicas, tais como a abertura comercial e a privatização de serviços públicos, entre outras, aprofundaram a internacionalização de alguns segmentos da economia e o encolhimento de outros, enquanto algumas atividades, como o agronegócio, por exemplo, se fortaleceram.

Mais recentemente, com o aumento da demanda internacional por produtos primários e insumos básicos, impulsionado, principalmente, por países como China e Índia, consolidou-se o que alguns autores denominam de re-primarização da economia brasileira, ancorada na produção e exportação de commodities minerais e agrícolas (Gonçalves, 2002). Tal opção significou um grande impulso na produção de energia, minérios, siderurgia, construção naval, metal-mecânica e química, entre outros, além dos produtos agropecuários, o que vem demandando uma grande quantidade de grandes investimentos $(\mathrm{GIs})^{4}$ em áreas estratégicas, tais como infraestrutura e logística de transporte, armazenagem e comunicação.

Esses GIs ocorrem nos contextos do PAC, da expansão da produção de petróleo e gás no Pós-Sal e do início da produção na camada de Pré-Sal, da ampliação da participação internacional do agronegócio brasileiro e da estratégia de consolidação do país como grande produtor e exportador de commodities primárias e produtos semiacabados.

\footnotetext{
${ }^{4}$ Para uma definição dos GIs, consultar Vainer (2007) e Piquet (2010). GIs são investimentos de grande porte, em termos nacionais e/ou internacionais, que encerram forte potencial de impactos territoriais, econômicos e sociais, pela elevada capacidade de mobilização de recursos e de articulação de escalas territoriais de poder.
} 
Autores como Brandão (2007), Vainer (2007), Gonçalves (2002), Araujo (2000) e Pacheco (1998) têm se dedicado a apontar o padrão periférico de integração internacional da economia brasileira na atual rodada da globalização capitalista, dado, entre outros, pelo fato de que não está apoiado na produção e exportação de produtos industrializados de alta tecnologia e numa base nacional de produção de ciência e tecnologia (C\&T) (teoria e pesquisa pura e básica) e pesquisa e desenvolvimento (P\&D) de produtos (estudos e pesquisas comprometidos com a criação de produtos para o mercado), bem como na priorização da integração regional e social.

Tal padrão, segundo esses autores, promove a incorporação de novas fronteiras territoriais e de áreas estagnadas do território brasileiro aos investimentos vinculados ao mercado internacional, produzindo vetores de fragmentação territorial e social. Fragmentos do território nacional são contemplados com investimentos articulados de fora e para fora, pela lógica da mundialização do mercado que, embora dinâmicos, em termos de mercado de trabalho, renda e crescimento econômico e urbano, não contribuem para a integração do território, para a irradiação espacial do dinamismo econômico gerado, ou para a minimização das desigualdades socioespaciais, reproduzindo enclaves enquanto ilhas de prosperidade.

É dominado por forças sociais que atuam no sentido contrário ao da incorporação ou integração das atividades econômicas e dos segmentos sociais regionais e locais, ou seja, da territorialização de parte significativa do excedente econômico e do seu direcionamento para a diversificação, integração e modernização das economias locais e regionais. Esse padrão de internacionalização da economia brasileira é denominado "desintegração competitiva", ou de integração "subordinada" ou "passiva" (Araújo, 2000; Pacheco, 1998). São empreendimentos que carregam características de "enclave" e de novas monoculturas, dado o grau de concentração e polarização que possuem (Piquet, 2007).

Os dados da participação do Brasil no comércio mundial de commodities fornecem uma ideia dessa inserção, registrados nas Figuras 3 e 4.

Figura 3. Brasil. Posição no ranking mundial das exportações de minério 


\begin{tabular}{|c|c|c|c|c|}
\hline $\begin{array}{l}\text { EXPORTADOR IGLOBAL } \\
\text { PLAYERI }\end{array}$ & EXPORTADOR & AUTOSSUFICIENTE & $\begin{array}{l}\text { IMPORTADOR } \\
\text { / PRODUTOR }\end{array}$ & DEPENDÊNCIA EXTERNA \\
\hline $\begin{array}{l}\text { Nióbio }\left[1^{\circ}\right] \\
\text { Minério de ferro }\left[1^{\circ}\right] \\
\text { Manganês }\left(2^{\circ}\right] \\
\text { Tantalita }\left(2^{\circ}\right)\end{array}$ & $\begin{array}{l}\text { Niquel } \\
\text { Magnésio } \\
\text { Caulim } \\
\text { Estanhe }\end{array}$ & $\begin{array}{l}\text { Calcário } \\
\text { Diamante Industrial } \\
\text { Titânio }\end{array}$ & & $\begin{array}{l}\text { Carvão Metalúrgico } \\
\text { Potássio }\end{array}$ \\
\hline $\begin{array}{l}\text { Grafite }\left(30^{\circ}\right) \\
\text { Bauxita }\left(2^{\circ}\right) \\
\text { Rochas } \\
\text { Ornamentais }\left(4^{\circ}\right)\end{array}$ & $\begin{array}{l}\text { Vermiculita } \\
\text { Cromo } \\
\text { Ouro }\end{array}$ & $\begin{array}{l}\text { Cobré } \\
\text { Tung-stênio } \\
\text { Talcọ }\end{array}$ & $\begin{array}{l}\text { Fosfato } \\
\text { Diatomito } \\
\text { Zinco }\end{array}$ & $\begin{array}{l}\text { Enxofre } \\
\text { Terras raras }\end{array}$ \\
\hline
\end{tabular}

Fonte: Informações e Análise da Economia Mineral Brasileira. IBRAM-Instituto Brasileiro de Mineração, 2011. www.ibram.org.br

Figura 4. Brasil no ranking mundial de commodities agropecuárias e agroindustriais

\begin{tabular}{|c|c|c|c|c|}
\hline \multirow{2}{*}{ Principais produtos } & \multicolumn{2}{|c|}{ Produção } & \multicolumn{2}{|c|}{ Exportação } \\
\hline & $2008 / 09$ & $2018 / 19$ & $2008 / 09$ & $2018 / 19$ \\
\hline Açúcar & $1^{5}$ & $1^{5}$ & $1^{\circ}$ & $1^{6}$ \\
\hline Café & $1^{10}$ & $\mathrm{n} / \mathrm{d}$ & $1^{\circ}$ & $\mathrm{n} / \mathrm{d}$ \\
\hline Suco de laranja & $1^{\circ}$ & $\mathrm{n} / \mathrm{d}$ & $1^{\circ}$ & $1^{\circ}$ \\
\hline Complexo soja & $\underline{2}^{0}$ & $2^{\circ}$ & $2^{\circ}$ & $1^{0}$ \\
\hline Carne bovina & $2^{0}$ & $2^{0}$ & $1^{0}$ & $1^{0}$ \\
\hline Tabaco & $2^{\circ}$ & $\mathrm{n} / \mathrm{d}$ & $1^{\circ}$ & $\mathrm{n} / \mathrm{d}$ \\
\hline Álcool & $2^{00}$ & $2^{0}$ & $1^{0}$ & $1^{0}$ \\
\hline Carne de frango & $3^{\circ}$ & $3^{\circ}$ & $1^{\circ}$ & $1^{\circ}$ \\
\hline Milho & $4^{\circ}$ & $4^{\circ}$ & $3^{\circ}$ & $3^{\circ}$ \\
\hline Carne suína & $4^{10}$ & $4^{0}$ & $4^{\circ}$ & $\underline{\underline{2}}^{0}$ \\
\hline
\end{tabular}

Fonte: Ministério da Agricultura, Pecuária e Abastecimento/Câmara Setorial Açúcar e Álcool. http://www.agricultura.gov.br/camaras-setoriais-e-tematicas $\mathrm{n} / \mathrm{d}$ : informação não-disponível

Os dados apresentados nas duas figuras revelam o protagonismo do país e a importância da economia exportadora de commodities agropecuárias, agroindustriais e minerais. O porte dessa economia condiciona o conjunto dos investimentos que recortam o território brasileiro voltados para dar-lhe suporte, ao mesmo tempo em que sua lógica vinculada à competitividade no mercado internacional induzem à omissão e negligência quanto às potencialidades dessa infraestrutura para um projeto de busca de equidade e justiça espacial e social no desenvolvimento brasileiro.

A esse respeito, cite-se trecho de artigo recente de Rubens Barbosa, na seção de opinião d'O Globo, em que destaca a 
... tendência de concentração da produção de manufaturas em poucos países, e à fragmentação da produção de bens industriais... o comércio das cadeias produtivas vem crescendo...Trata-se do intercâmbio de bens, investimentos, serviços e tecnologia, associado às redes internacionais de produção, que combinam a inovação em países desenvolvidos com salários baixos dos países em desenvolvimento... ao ficar de fora do circuito das cadeias produtivas globais, a maioria dos países em desenvolvimento, inclusive o Brasil, passa a concentrar suas exportações em commodities e suas exportações de manufaturados tornam-se cada vez mais reduzidas. (Barbosa, 2013:19)

Ao mesmo tempo, algumas das âncoras da retomada do crescimento brasileiro e fluminense despertam incertezas e inseguranças quanto à sua sustentabilidade, como nos casos do petróleo, do aço e dos automóveis, que constituem alguns dos sustentáculos da retomada do crescimento fluminense e brasileiro. Ao invés de assistir passivamente ao crescimento do Brasil como grande abastecedor mundial de petróleo e aço, por exemplo, o mundo assiste a um recrudescimento dos investimentos na produção de petróleo em grandes países; o crescimento da produção de óleo e gás do xisto betuminoso; o crescimento das fontes alternativas ao petróleo, como a eólica e solar; e a retomada da energia nuclear, entre outras fontes alternativas renováveis de energia. Os países centrais retomam suas estratégias de produção de aço, e países como a China buscam diminuir sua dependência, ao passo que a crise econômica mundial cuidou de reduzir a demanda externa pelo produto brasileiro.

Quanto à indústria automotiva, esta está investindo na perifeira capitalista para além da capacidade de consumo mundial, exacerbando deformações já existentes na estrutura de mobilidade urbana desses países, e gestando uma crise futura de graves proporções. Para ilustrar, Miriam Leitão, na sua coluna d'O Globo afirma: "Há 25 milhões de carros ociosos no mundo, e mais de 500 milhões de toneladas de aço" (Leitão, 2013:28). Alguns fatos reforçam essas afirmações, tais como os subsídios que a indústria automotiva demanda e a suspensão e o cancelamento de diversos projetos de ampliação e construção de siderúrgicas no país.

Outro aspecto relevante a considerar, e que tem a ver diretamente com a questão do desenvolvimento territorial, regional e social, diz respeito ao porte desses investimentos privilegiados pela retomada do crescimento no Brasil, em geral, e no ERJ, em particular. À escala nacional é o caso das grandes hidrelétricas, cujos impactos negativos decorrem, em grande parte, das suas dimensões, pela capacidade, que encerram, de (des)estruturação do território, dos sistemas produtivos, sociais e ambientais. 
No ERJ é o caso do Complexo do Açu, um GI, cujo impacto no crescimento urbano, rápido e exponencial, já se faz sentir pelo deslocamento "involuntário" de população de áreas econômicas produtivas; pela desestruturação de atividades tradicionais, como a pesca; pelo prejuízo em toda a cadeia produtiva, com a salinização da água do lençol freático, utilizada, entre outras finalidades, na produção agrícola; com a demanda de água do Paraíba, que afetará a capacidade de atendimento da demanda urbana regional; com a incrustação no território do Corredor Logístico - murado, com cerca de 400m de largura, compreendendo, mineroduto, ferrovia e rodovia - atravessando terras produtivas e áreas de assentamentos de reforma agrária, entre outros aspectos, que estão a motivar a apresentação de proposta de diminuição do porte do projeto, por parte da sociedade e dos movimentos sociais, articulados de forma multiescalar. Algo semelhante pode ser esperado para o COMPERJ, embora com suas particularidades.

A título de ilustração, mesmo em plena vigência da economia regional do petróleo no Norte Fluminense, a população dos municípios do NF cresceu a taxas médias mais baixas que a média estadual e nacional, até os anos 2000, mesmo no município de Campos dos Goytacazes, tradicional polo regional, fronteiriço ao município de Macaé. A exceção foi Macaé, sede das instalações da Petrobras, já que as elevadas taxas de Quissamã e Carapebus se devem ao fato de terem se emancipado de Macaé, no período.

Só a partir da injeção das rendas petrolíferas e do início das obras civis do Complexo Portuário, Logístico e Industrial do Açu (CLIPA), em 2007, é que essas taxas reagiram e passaram a se situar acima das médias estadual e nacional, o que se refletiu somente no Censo Demográfico de 2010, do IBGE. Tal fenômeno, no entanto, só foi observado nos municípios de Campos e São João da Barra, ambos recebedores das rendas e diretamente beneficiados pelo CLIPA.

Esses GIs possuem, ainda, potencial do que se pode denominar uma espécie de “criação destrutiva", para nomear uma relação custo/benefício negativa, que contrapõe ao seu potencial de industrialização e de geração de trabalho e renda vetores de devastação de estruturas e dinâmicas produtivas preexistentes, sem a contrapartida da reintegração positiva das populações atingidas, bem como vetores de constituição de novas e ampliação de antigas periferias urbanas precárias, dada a inoperância demonstrada pelo poder público no atendimento das demandas de equipamentos e infraestruturas urbanas no volume e ritmo requeridos. 
O poder de concentração e polarização tende a produzir, localmente, um excedente relativo de população e de força de trabalho, formado por migrantes e residentes antigos não incorporados ao mercado de trabalho e à cidade, bem como um rápido e acentuado adensamento urbano sem a devida contrapartida da infraestrutura e dos serviços, o que pode resultar na desordem urbana, na expansão da favelização, da pobreza e da miséria, do desemprego e do subemprego, da exclusão social e, no limite, da violência e da penetração do crime organizado. Tende a ocorrer aumento da segregação e fragmentação sociais e territoriais, agravando periferias já existentes e produzindo novas, no entorno dos municípios e microrregiões contempladas, como é o caso do município de Macaé (Cadena e Costa, 2012), que concentra as instalações físicas do Complexo Regional de E\&P, da Bacia de Campos, no NF.

Os GIs, como um dos vetores desse padrão, via de regra, produzem significativa geração de postos de trabalho e um grande volume de investimentos em capital fixo, dinamizando serviços, a construção civil e a implantação de equipamentos urbanos e de serviços públicos, o que atrai população e pressiona as estruturas urbanas. Apesar da volumosa injeção de recursos financeiros nas instalações e equipamentos, esses tendem a se efetivar de forma concentrada e segregada, em termos econômicos, sociais e espaciais, agravando a hierarquia e a seletividade entre municípios contemplados e municípios excluídos. A implantação e expansão do Complexo de E\&P, no Norte do Estado do Rio, a partir da segunda metade dos anos 70 do século passado, reforça essas observações. ${ }^{5}$

\section{Aspectos importantes da herança socioeconômica fluminense}

Após apresentar um breve quadro do perfil do padrão de crescimento econômico que se desenha no ERJ e de tecer considerações a respeito dos impactos socioeconômicos e socioespaciais desse padrão, segue a análise de uma seleção de indicadores, para além dos estritamente econômicos, com o intuito de dimensionar a complexidade e a profundidade do desafio de transformação de crescimento em desenvolvimento, o que retoma os vínculos do futuro da economia fluminense com o futuro do desenvolvimento brasileiro.

Entre 2002 e 2010, o ERJ foi o penúltimo estado em crescimento acumulado do PIB, de 25,6\%, contra 37,1\% do Brasil, de acordo com as Contas Regionais do Brasil, do

\footnotetext{
${ }^{5}$ Para um balanço da economia regional do petróleo no NF, ver Piquet (2003) e Piquet e Serra (2007).
} 
IBGE. Significa que o ERJ continua com taxa média e acumulada de crescimento do PIB inferior à média e ao acumulado brasileiro e o crescimento recente não alterou essa tendência. No entanto, Silva (2012) destaca que se trata de um crescimento expressivo, "considerando ter sido alcançada por uma economia madura" (Silva, 2012:206), além do fato de as taxas médias nacionais terem sido influenciadas pelos baixos patamares estatísticos como ponto de partida de alguns estados.

Salvo algumas áreas específicas, a produção agropecuária estadual mantém baixos patamares tecnológicos e de competitividade, o que, aliado à polarização da economia do petróleo e dos investimentos recentes, tende a agravar o quadro de definhamento das atividades agropecuárias e agroindustriais no estado, como se pode observar na manutenção do declínio da área plantada total, nos anos recentes, conforme a Tabela 7.

Tabela 7. Área plantada - total

\begin{tabular}{|c|c|c|c|c|c|c|c|}
\hline Sigla & Código & Estado & 2006 & 2007 & 2008 & 2009 & 2010 \\
\hline $\mathbf{A C}$ & 12 & Acre & 126861 & 123843 & 113055 & 94431 & 128842 \\
\hline $\mathbf{A L}$ & 27 & Alagoas & 640693 & 642400 & 675646 & 650778 & 612287 \\
\hline $\mathbf{A M}$ & 13 & Amazonas & 209508 & 183247 & 181694 & 184691 & 171943 \\
\hline $\mathbf{A P}$ & 16 & Amapá & 16289 & 17871 & 21079 & 23520 & 25387 \\
\hline BA & 29 & Bahia & 4839023 & 4808188 & 4860058 & 4775228 & 4691980 \\
\hline CE & 23 & Ceará & 1858769 & 1942332 & 2013268 & 2076295 & 1769179 \\
\hline DF & 53 & Distrito Federal & 124876 & 128440 & 132665 & 122142 & 119198 \\
\hline ES & 32 & Espírito Santo & 769873 & 747510 & 733297 & 726017 & 692698 \\
\hline GO & 52 & Goiás & 4076892 & 3955025 & 4225916 & 4446666 & 4511942 \\
\hline MA & 21 & Maranhão & 1644964 & 1657791 & 1667117 & 1624638 & 1765850 \\
\hline MG & 31 & Minas Gerais & 4724964 & 4598477 & 4740522 & 4789178 & 4844245 \\
\hline MS & 50 & Mato Grosso do Sul & 3009887 & 3038492 & 3193802 & 3151273 & 3190090 \\
\hline MT & 51 & Mato Grosso & 8063237 & 8048076 & 8915519 & 8821813 & 9432603 \\
\hline PA & 15 & Pará & 1239015 & 1205822 & 1148344 & 1103914 & 1049016 \\
\hline PB & 25 & Paraíba & 661566 & 613509 & 667808 & 659333 & 447155 \\
\hline PE & 26 & Pernambuco & 1135448 & 1134392 & 1300243 & 1188327 & 1095900 \\
\hline PI & 22 & Piauí & 1169358 & 1199610 & 1200622 & 1279114 & 1260983 \\
\hline PR & 41 & Paraná & 9246533 & 9403434 & 9810281 & 10073403 & 9708216 \\
\hline RJ & 33 & Rio de Janeiro & 257134 & 219874 & 218120 & 214895 & 214265 \\
\hline $\mathbf{R N}$ & 24 & Rio Grande do Norte & 471129 & 456909 & 474912 & 488137 & 340333 \\
\hline RO & 11 & Rondônia & 604103 & 593956 & 622051 & 630866 & 652066 \\
\hline $\mathbf{R R}$ & 14 & Roraima & 62185 & 49395 & 53643 & 42343 & 42193 \\
\hline RS & 43 & Rio Grande do Sul & 7963724 & 7985324 & 8020367 & 8002053 & 7876958 \\
\hline SC & 42 & Santa Catarina & 1789783 & 1767763 & 1760642 & 1731340 & 1667836 \\
\hline SE & 28 & Sergipe & 432473 & 403710 & 409269 & 418407 & 458332 \\
\hline
\end{tabular}




\begin{tabular}{lrlrrrrr}
\hline SP & 35 & São Paulo & 6828724 & 6832410 & 7576405 & 7635141 & 7790365 \\
TO & 17 & Tocantins & 599269 & 588061 & 641703 & 605113 & 654079 \\
\hline
\end{tabular}

Área plantada - total. ERJ $=-17 \%$.

Fonte: Instituto Brasileiro de Geografia e Estatística

Frequência: Anual de 1988 até 2010. Unidade: Hectare. Atualizado em:24/11/2011www.ipeadata.gov.br

De acordo com os dados da Tabela 7, entre 2006 e 2010 o ERJ foi o quarto colocado entre os estados que mais reduziram a área plantada total; os três primeiros foram Paraíba, Roraima e Rio Grande do Norte. Na região Sudeste só o ES também teve sua área reduzida, ao passo que esta aumentou em Minas Gerais e São Paulo.

Nos últimos anos a participação da indústria extrativa no valor adicionado da indústria fluminense cresceu, enquanto a da indústria de transformação diminuiu, seguidos pela construção civil e os serviços industriais (Silva, 2012), muito embora os investimentos anunciados e em curso na indústria de transformação possam vir a melhorar esse quadro. Já o setor de serviços vem diminuindo sua participação no PIB estadual.

Tabela 8. Participação dos Setores no VAB do ERJ, em 1995 e 2009 (\%)

\begin{tabular}{lcc}
\hline Setores & $\mathbf{1 9 9 5}$ & $\mathbf{2 0 0 9}$ \\
\hline Agricultura e Agropecuária & 0,89 & 0,41 \\
Indústria & 19,55 & 26,35 \\
Extrativa & 1,25 & 8,32 \\
de Transformação & 9,80 & 10,12 \\
Construção Civil & 6,55 & 5,20 \\
Serviços & 79,64 & 73,16 \\
\hline & 1,68 & 0,86 \\
\hline Agricultura e Agropecuária & 7,88 & 10,80 \\
Indústria & 17,10 & 49,16 \\
Extrativa & 5,90 & 6,96 \\
de Transformação & 13,37 & 10,77 \\
Construção Civil & 13,38 & 11,96 \\
Serviços & do Brasil, por setores, em $\mathbf{1 9 9 5}$ e &
\end{tabular}

Fonte: IBGE, FESP/CEPERJ/CEEP, elaboração própria. VAB = Valor Adicionado Bruto. É o resultado final da atividade produtiva no decurso de um período determinado. Resulta da diferença entre o valor da produção e o valor do consumo intermédio, originando excedentes. 
A Tabela 8 reflete a inflexão recente da economia fluminense, com a retomada de investimentos industriais, aqui assinalados, particularmente na petroquímica, siderurgia, indústria naval e automotiva, o que eleva o peso desse setor, tanto no VAB estadual quanto no nacional. No entanto, o mesmo dado serve para revelar o quanto o estado tem na indústria extrativa (leia-se petróleo e gás) seu sustentáculo.

Assim como foi observado no caso aqui analisado, da região $\mathrm{NF}$, que sedia o Complexo de Exploração e Produção de Petróleo e Gás, essa crescente dependência da economia do petróleo não foi acompanhada de melhoria nos indicadores socioeconômicos estaduais.

No que toca à variação do emprego formal, os dados de 1995 a 2005 refletem os estudos que assinalam a inflexão ocorrida a partir da segunda metade da década de 1990, muito embora o perfil negativo permaneça. No período de 1995 a 2005, a taxa de crescimento do ERJ foi a pior do Brasil, conforme a Tabela 9, tanto no conjunto quanto na indústria, em particular; sendo que, nesta última, foi o único estado que apresentou índice negativo no período. Considerando-se os dados em separado para a RMRJ e para o interior, este teve índices bem superiores à média brasileira em todos os intervalos da tabela, ao passo que a RMRJ teve índices bem inferiores à média brasileira nos mesmos períodos.

Tabela 9. Variação do emprego formal. BRASIL E ERJ - 1995-2005

\begin{tabular}{lccc}
\hline Unidade & $\mathbf{1 9 9 5 - 1 9 9 9}$ & $\mathbf{1 9 9 9 - 2 0 0 5}$ & $\mathbf{1 9 9 5 - 2 0 0 5}$ \\
\hline Brasil & 5,3 & 33,0 & 40,0 \\
\hline ERJ (não-metropolitana) & 8,5 & 52,1 & 65,0 \\
\hline ERJ (região metropolitana) & $-3,8$ & 13,7 & 9,3 \\
\hline ERJ (total estado) & $-1,7$ & 20,8 & $18,7 *$ \\
Na Indústria & $1995-1999$ & $1999-2005$ & $1995-2005$ \\
Brasil & $-6,0$ & 33,2 & 25,0 \\
ERJ & $-20,6$ & 9,6 & $-12,90 * *$ \\
\hline
\end{tabular}

*Último lugar no Brasil. **Último lugar no Brasil, único com índice negativo.

Fonte: RAMOS, Lauro. Evolução e realocação do emprego formal. Economia, Rio de Janeiro, V.9, N.1, p. 89-112, junho 2007. Elaboração própria.

http://search.conduit.com/Results.aspx?q=economica\%2C+rio+de+janeiro\%2C+v.9\%2C+n.1\%2C+p.+89$112 \% 2 C+$ junho+2007\&SearchSource $=49 \&$ ctid $=$ CT3227982. Consultado em 27/08/2012. 
Quanto aos índices de desemprego, a taxa média de desemprego no ERJ no ano de 2010 foi de 8,9\%, sem grandes disparidades entre as regiões (SEBRAE, 2012).

No que toca à desigualdade social, utilizando-se o índice de Gini, há uma ligeira melhoria entre 2005 e 2009, acompanhando a tendência geral no Brasil. O índice de Gini do ERJ situa-se na média brasileira, que é bastante elevada. Dentre os estados do Sudeste, é o de maior desigualdade, conforme se pode observar na Tabela 10.

Tabela 10. Desigualdade Social pelo Coeficiente de Gini*

\begin{tabular}{lrrrrr}
\hline Estado & $\mathbf{2 0 0 5}$ & $\mathbf{2 0 0 6}$ & $\mathbf{2 0 0 7}$ & $\mathbf{2 0 0 8}$ & 2009 \\
\hline Espírito Santo & 0,558196 & 0,536697 & 0,526068 & 0,521005 & 0,531619 \\
Minas Gerais & 0,527397 & 0,527927 & 0,517323 & 0,515269 & 0,512881 \\
Rio de Janeiro & 0,556646 & 0,555035 & 0,548836 & 0,539931 & 0,542411 \\
São Paulo & 0,53215 & 0,524671 & 0,506632 & 0,501987 & 0,489408 \\
Brasil & $\mathbf{0 , 5 6 9 4 3 8}$ & $\mathbf{0 , 5 6 2 9 3 6}$ & $\mathbf{0 , 5 5 6 0 4 3}$ & $\mathbf{0 , 5 4 7 5 6 3}$ & $\mathbf{0 , 5 4 2 7 5 1}$ \\
\hline
\end{tabular}

*Quanto mais próximo de 1 mais desigual.

Fonte: IPEADATA, 27/08/2012, 11:46. http://www.ipeadata.gov.br/. Elaboração própria.

Dentre os indicadores que contemplam os aspectos qualitativos e distributivos do crescimento econômico, destaca-se o do peso do trabalho na composição da renda, pela sua contribuição para o dimensionamento das desigualdades sociais. Nesse aspecto o ERJ se encontrava, em 2000, na sexta pior colocação entre os estados brasileiros na distribuição funcional da renda, relativa ao percentual da renda do trabalho no total estadual, tendo essa participação sofrido uma queda de mais de $16 \%$ no período considerado na Tabela 11.

Tabela 11. Renda. Rendimento do trabalho

\begin{tabular}{lrr}
\hline Estado & $\mathbf{1 9 9 1}$ & $\mathbf{2 0 0 0}$ \\
\hline Acre & 86,062 & 69,981 \\
\hline Alagoas & 79,963 & 61,635 \\
\hline Amazonas & 84,8 & 67,059 \\
\hline Amapá & 87,766 & 71,915 \\
Bahia & 81,398 & 63,652 \\
Ceará & 82,607 & 65,666 \\
Distrito Federal & 88,291 & 74,014 \\
\hline Espírito Santo & 84,434 & 71,321 \\
Goiás & 87,117 & 74,583 \\
\hline Maranhão & 83,842 & 66,402 \\
Minas Gerais & 83,553 & 69,691 \\
\hline Mato Grosso do Sul & 89,329 & 74,595 \\
\hline
\end{tabular}




\begin{tabular}{|lrr|}
\hline Mato Grosso & 89,825 & 74,721 \\
\hline Pará & 86,628 & 68,925 \\
\hline Paraíba & 76,921 & 63,167 \\
\hline Pernambuco & 79,365 & 62,085 \\
\hline Piauí & 81,282 & 66,652 \\
\hline Paraná & 86,164 & 73,745 \\
\hline Rio de Janeiro & 77,227 & 64,742 \\
\hline Rio Grande do Norte & 79,611 & 63,118 \\
\hline Rondônia & 86,97 & 71,88 \\
\hline Roraima & 78,903 & 76,271 \\
\hline Rio Grande do Sul & 82,212 & 70,822 \\
\hline Santa Catarina & 84,979 & 73,032 \\
\hline Sergipe & 81,5 & 65,429 \\
\hline São Paulo & 84,392 & 71,733 \\
\hline Tocantins & 88,313 & 69,751 \\
\hline
\end{tabular}

Fonte: IPEA. http://www.ipeadata.gov.br/. Atualizado em 08/07/2011

Obs. Equivale à participação percentual das rendas provenientes do trabalho (principal $\mathrm{e}$ outros) na renda total.

Para compor um quadro, ainda que parcial e limitado, da situação socioeconômica do ERJ, é importante destacar que, no que diz respeito à Educação, em 2009 o estado ocupava a segunda pior posição dentre todos os estados brasileiros, no ensino médio, segundo o Índice de Desenvolvimento da Educação Básica (IDEB/MEC). No que diz respeito à questão metropolitana, o conjunto de indicadores apontam a ocorrência, no período pós-60, de uma particular degradação da periferia da RMRJ, no cenário das metrópoles existentes na Região Sudeste. Entre os indicadores, pode-se citar, por exemplo, o fato de que, num ranking dos resultados do IDEB/MEC para a educação básica pública, no ano de 2009, na periferia das Regiões Metropolitanas do Rio de Janeiro, São Paulo e Belo Horizonte, verifica-se que todos os piores resultados estão na periferia da RMRJ (Silva, 2013).

Quanto à proteção à saúde da população, o ERJ é uma das 3 piores unidades da federação, ao lado do Pará e de Rondônia, no Índice de Desempenho do SUS nos Estados (MS/IDSUS, 2012).

Finalmente, o quadro estadual das condições socioeconômicas apresentado até aqui, embora não autorize afirmações peremptórias gerais, permite, em parte, perceber a existência de uma conjugação de fatores que respondem pelos graves índices de violência no estado, particularmente contra os jovens, conforme se observa na Tabela 12. O ERJ 
evoluiu da $3^{\mathrm{a}}$ para a $7^{\mathrm{a}}$ pior posição no país, na taxa de homicídios, com relação à população total, e da $2^{\mathrm{a}}$ para a $5^{\mathrm{a}}$ pior colocação na taxa de homicídios entre os jovens de 15 a 24 anos, ou seja, na faixa etária mais produtiva, o que está em consonância com o problema detectado na educação em geral, e no ensino médio, em particular, entre outros fatores. Apesar da evolução, suas taxas continuam mais elevadas que as taxas médias brasileiras.

Tabela 12.Taxa de homicídio (em 100 mil), BRASIL E ERJ (n\%/posição) - 1998 e2008

\begin{tabular}{lcc}
\hline Na população total & $\mathbf{1 9 9 8}$ & $\mathbf{2 0 0 8}$ \\
\hline Brasil & 25,9 & 26,4 \\
ERJ & $55,3 / 3^{\circ}$ & $34 / 7^{\circ}$ \\
\hline Na população de jovens de $\mathbf{1 5}$ a 24 anos & $\mathbf{1 9 9 8}$ & $\mathbf{2 0 0 8}$ \\
\hline Brasil & 47,7 & 52,9 \\
ERJ & $110,7 / 2^{\circ}$ & $76,9 / 5^{\circ}$ \\
\hline
\end{tabular}

Fonte:AISELFISZ, Júlio J. Mapa da Violência 2011 - Os jovens do Brasil. Instituto Sangari/Ministério da Justiça. http://mapadaviolencia.org.br/, consultado em 28/08/2012. Elaboração própria.

\section{Considerações finais}

É fato irrefutável que ocorre uma retomada do crescimento econômico de grande importância, no ERJ, cujas características encerram importante potencial de uma maior e melhor distribuição espacial dos investimentos em $\mathrm{k}$ fixo e do emprego, em termos do número de regiões beneficiadas e da qualidade dos investimentos. Estes têm sido expressivos no segmento industrial, com algumas atividades de ponta; e no de logística, com projetos e ações que envolvem toda a orla marítima estadual. Como resultado, o interior do estado apresenta um ritmo de crescimento superior ao da região metropolitana. Tal fato se repete na RMRJ, nos municípios periféricos à capital.

Pode-se afirmar que existe um movimento consistente de interiorização e regionalização expandida das atividades econômicas, o que revela um processo de desconcentração relativa da dinâmica econômica estadual. Tal fenômeno oferece perspectivas de redução da excessiva centralização e concentração de investimentos e recursos na RMRJ e, nela, no município da capital, o RJ-M.

O ERJ carrega uma herança de concentração e desigualdade econômica, espacial e social que devem ocupar posição central na discussão do seu desenvolvimento, exposta neste artigo e que podem ser representadas na precariedade das condições de urbanização no interior, decorrentes do longo período de depressão e estagnação econômicas; na 
qualidade da educação básica, a cargo dos municípios, mas também do ensino fundamental, o que inclui a responsabilidade do governo estadual; na baixa qualificação da força de trabalho, egressa de atividades agropecuárias e agroindustriais extintas, ou encolhidas; na precarização das condições de trabalho, herança das relações de trabalho no campo, das atividades informais e do subemprego imperantes no interior do estado; nos elevados índices de violência, dadas as condições socioeconômicas históricas e atuais e, mais recentemente, as ações de combate ao crime na capital.

Não foi possível articular todas essas dimensões, mas, ao apresentar um conjunto diversificado de indicadores, buscou-se apontar a complexidade do fenômeno do desenvolvimento, na assimetria entre essas dimensões e na importância de se colocar a questão das desigualdades no centro da análise, especificamente no que diz respeito ao mundo do trabalho, como uma dimensão privilegiada.

Nesse sentido, a retomada do desenvolvimento do ERJ exacerba várias questões estruturais do estado e da nação.

No segmento do petróleo e gás, que tem sido o principal responsável pela retomada, tem-se uma dicotomia entre as dinâmicas espaciais das atividades extrativistas, localizadas no Norte e nas Baixadas Litorâneas, e das beneficiadoras, na RMRJ, onde ocorre o maior investimento, o COMPERJ. Ao Norte ocorreu um processo de concentração espacial e social dos benefícios monetários e econômicos diretos, agravando problemas de acesso à terra e de adensamento, infraestrutura e mobilidade urbanos, embora alguns municípios da BL tenham sido beneficiados com instalações físicas.

No complexo petroquímico, o porte do COMPERJ vis a vis o planejamento e as intervenções na infraestrutura urbana e de mobilidade permitem antever o agravamento da herança de desigualdades e dos baixos indicadores persistentes no entorno do Rio de Janeiro e no Leste estadual. Trata-se, no entanto, de um segmento que tem grande poder de ramificação em atividades industriais já implantadas no estado, como a química e a farmacêutica.

No segmento da indústria de transformação, outro dos principais vetores da retomada, quando se analisa um dos seus pilares - os ramos automotor e metal-mecânico -, alguns aspectos devem ser considerados: o superdimensionamento da sua capacidade, tanto no Brasil quanto no mundo; sua matriz energética não renovável, que é objeto de investidas internacionais, crescentes e intensas, no sentido da sua inflexão, todas em curso 
fora do país; as implicações na mobilidade urbana, um dos pontos mais graves da tragédia urbana brasileira; os riscos ambientais dos ramos metalúrgico e siderúrgico; e sua dependência tecnológica externa.

Além disso, seu patamar tecnológico e o grau de encadeamento internacional atuais limitam a capacidade de geração de trabalho; seus segmentos industriais a montante e a juzante estão, na maior parte, fora do território estadual e nacional; e os centros de decisão das estratégias de investimento se encontram no exterior. Finalmente, os estudos aqui citados têm mostrado sua relativamente baixa capacidade de dispersão territorial e de integração regional ampla. Neste segmento tem destaque, ainda, o ramo da indústria naval, que retroalimenta a metal-mecânica e se encontra altamente dependente da exploração de petróleo e gás da plataforma marítima e de tecnologia externa.

No segmento de infraestrutura cabe destacar, como contribuição a esta síntese final, que o grande volume de intervenções, ao obedecer às estratégias que vêm orientando os investimentos nesse segmento em todo o país, no tocante a rodovias e ferrovias, a portos e aeroportos, ignora as demandas inerentes ao desenvolvimento social, urbano e regional. As cidades e os aglomerados produtivos onde não existem nós da cadeia territorial de formação de valor são obstáculos ao traçado das vias de circulação de mercadorias. Nas intervenções da capital, voltadas para dar suporte a uma economia de cultura e entretenimento, as formações de novas periferias segregadas é uma ameaça concreta.

A inexistência de uma estratégia nacional, e/ou estadual, de promoção dessa integração tende a agravar os problemas econômicos, sociais, territoriais e urbanos, às escalas local, micro, meso e macrorregionais, do ERJ, uma vez que tais investimentos, ao gerar novas polarizações e centralidades, não são passivos. Deslocam prioridades, promovendo destruições simbólicas e concretas, ao desestruturar aglomerados urbanos e dinâmicas produtivas existentes e ao desmobilizar recursos que poderiam ser mobilizados para a criação de alternativas e de diversificação econômica.

Ocorre uma alienação das intervenções com relação às demandas de estruturação, complementaridade e integração dos espaços produtivos, de trabalho e de vida, ou seja, da sua contribuição para o desenvolvimento socioeconômico, urbano e regional. Já existem diversos focos de conflitos ligados aos deslocamentos forçados e expulsões de população de áreas urbanas e rurais, dedicadas a atividades produtivas, no interior e na capital, decorrentes tanto de intervenções de infraestrutura quanto de atividades produtivas. 
A transformação do território do ERJ em plataforma de infraestrutura de logística de circulação de mercadorias vinculadas ao padrão exportador de commodities minerais e agrícolas, e de bens intermediários, remete à discussão da capacidade dessa estratégia gerar desenvolvimento em termos espaciais e sociais, vinculados à ideia de justiça distributiva, em que a difusão social e territorial se ancorem em integração social, setorial, urbana e regional.

O conjunto dos impactos devem ser avaliados, a montante, na destruição de atividades e aglomerações residenciais e produtivas; na desagregação de estruturas e dinâmicas sociais e urbanas, e de subsistemas ambientais - sem as justas e apropriadas compensações e/ou alternativas, se é e quando se justificam; e a juzante, nos obstáculos que coloca à diversificação e expansão da dinamização gerada, em função de ser prisioneiro da lógica internacional de inserção local/regional, e pelo monopólio dos recursos políticos, ambientais, humanos, físicos, financeiros e materiais, dados pelas isenções e estímulos obtidos e ao seu poder de polarização e de concentração, reproduzindo, em alguns locais, verdadeiras monoculturas.

Dada a natureza e o contexto dos vetores da retomada do crescimento econômico fluminense e os expedientes utilizados para a localização, viabilidade e implementação desses investimentos, várias questões emergem e devem ser objeto de estudos, pesquisas e debates, bem como de ações articuladas de enfrentamento.

Qual a diversidade e a qualidade da estrutura do emprego? Como são gerados, a que custos sociais, econômicos, urbanos e territoriais? Quem se beneficia com esses empregos, em termos sociais, setoriais e espaciais? Qual o potencial de integração intersetorial e interurbana, às escalas intrarregional e inter-regional, dos investimentos? Quais são as estratégias multiescalares adequadas à construção de um desenvolvimento integrado, econômica, social, territorial e política, que articule, à escala estadual, as potencialidades históricas e atuais?

O ingresso do ERJ no circuito de recuperação da economia nacional pelas portas que lhe foram abertas, se, por um lado, iluminam estradas outrora precárias que vinha trilhando, por outro projetam novas sombras de incertezas e inseguranças, desequilíbrios e desigualdades. Essas zonas sombrias são extensões das que cobrem boa parte do país, na sua forma de inserção na divisão internacional do trabalho. 
No plano político, o ERJ e o país são reféns dos expedientes políticos caros à tradição brasileira que atuam, ao lado de outros, como obstáculos ao desenvolvimento, reproduzindo a modernização conservadora. Alguns deles são o clientelismo, o patrimonialismo, o autoritarismo e o aparelhamento da máquina pública.

Diversificar as atividades econômicas e buscar nas atividades produtivas a dinamização da economia afetam o empreguismo na administração pública. Mais além, diversificar a economia pela valorização e reforço de atividades de base local, micro e mesorregionais, de micro e pequenos empresários, ou de base familiar e associativa, atrapalha as estratégias de grandes investimentos, de capitais internacionais articulados pela dinâmica mundial, baseadas na apropriação e monopólio dos recursos existentes no território, materiais e imateriais.

Prover infraestrutura pública e de qualidade em escala socialmente universal se torna difícil na medida em que a especulação imobiliária, a privatização e elitização do acesso e da ocupação do solo e dos espaços públicos, materializados, por exemplo, no modelo imperante de condomínios de moradia e consumo privados e exclusivos, monopolizam os esforços e os recursos das administrações públicas na implantação de infraestrutura.

Atacar a precarização das relações de trabalho mina as bases de sustentação política dos grupos no poder, já que as corporações empresariais dos diversos ramos conseguem, com apoio político, blindar as suas práticas de exploração e de invisibilidade nas relações de trabalho.

Melhorar a educação implica redefinir radicalmente as prioridades dos governos municipais e estadual.

Enfrentar a violência pressupõe enfrentar todos os problemas anteriormente elencados.

Cumprir e zelar pelo cumprimento da legislação ambiental exige enfrentamentos dos interesses empresariais, corporativos e particulares que orientam os investimentos econômicos.

A construção do desenvolvimento no ERJ pressupõe o enfrentamento dos desafios do desenvolvimento brasileiro hoje. É necessário uma ação de planejamento orquestrada e integrada, às diversas escalas, com forte poder de interferência de organizações e 
movimentos que representam interesses hoje excluídos ou sufocados nas decisões de política econômica, de recorte regional e nacional.

\section{Referências bibliográficas}

AISELFISZ, Júlio J. Mapa da Violência 2011 - Os jovens do Brasil. Instituto Sangari/Ministério da Justiça, 2012. http://mapadaviolencia.org.br/

ARAÚJO, Tânia Bacelar. Ensaios sobre o desenvolvimento brasileiro: heranças e urgências. Rio de Janeiro: REVAN: Fase, 2000.

BARBOSA, Rubens. O Brasil fora das cadeias produtivas globais. O Globo, p. 19. Rio de Janeiro, 26 de fevereiro de 2013.

BRANDÃO, Carlos Território e Desenvolvimento. Campinas: Ed. UNICAMP, 2007.

CADENA, Alberto Silva; COSTA, Ricardo César Rocha. Macaé, capital do petróleo: desenvolvimento econômico, desigualdades sociais e expansão urbana. Macaé/RJ: Prefeitura Municipal de Macaé/Coordenadoria Geral do Programa Macaé Cidadão, 2012. 142p.

CRUZ, José Luis Vianna. A retomada do crescimento da economia fluminense pós-anos 90 do século XX: natureza e sentidos. Relatório de Pós-Doutorado. Rio de Janeiro: UFRRJ/PPGDT-Programa de Pós-Graduação em Desenvolvimento Territorial e Políticas Públicas, 2013. 69p.

A retomada do crescimento brasileiro e a reestruturação espaço regional no Norte do Estado do Rio de Janeiro. Revista Vértices. Instituto Federal de Educação, Ciência e Tecnologia Fluminense, v.14, n. especial 1, pp.31-61. Campos dos Goytacazes: Essentia Editora, 2012.

FIRJAN. Decisão Rio 2012-2014. Rio de Janeiro: FIRJAN, 2012. Disponível em: http://www.firjan.org.br/decisaoport2012-2014/files/decisaorio2012-2014_pt.pdf

. Demanda de logística de transporte de cargas para o Est. do Rio de Janeiro. Rio de Janeiro: FIRJAN, 2011.

. Retratos Regionais. Rio de Janeiro: FIRJAN, 2011. Disponível em: http://www.firjan.org.br/data/pages/402880811F3D2512011F7FE00F0B3401.htm

\section{IDEB/INEP/MEC.}

http://ideb.inep.gov.br/resultado/resultado/resultadoBrasil.seam?cid=11840

GONÇALVES, Reinaldo. Vagão descarrilhado: o Brasil e o futuro da economia global. Rio de Janeiro: Record, 2002.

LEITÃO, Míriam. O novo normal. $O$ Globo, p. 28. Rio de Janeiro, 26 de fevereiro de 2013. 
MS/IDSUS. Índice de Desempenho do SUS nos Estados. http://saladeinformacao.saude.gov.br/cartogramas/sage/abremapa.php?id=1, consultado em 28/08/2012.

NATAL, Jorge Luiz Alves. Inflexão econômica positiva e dinâmica regional. In: NATAL, J. (org.). O Estado do Rio de Janeiro pós 95. Rio de Janeiro: Armazém das Letras, 2007. pp. 45-61.

OLIVEIRA, Floriano José Godinho. Reestruturação produtiva, território e poder no Rio de Janeiro. Rio de Janeiro: Garamond, 2008. 304 p.

PACHECO, C. A. Fragmentação da nação. Campinas: Instituto de Economia/ UNICAMP, 1998. 291 p.

PIQUET, Rosélia. O Norte Fluminense em tempo presente. In: SANTOS, Angela; MARAFON, Glaucio; SANT'ANNA, Maria Josefina (orgs.). Rio de Janeiro: um olhar socioespacial. Rio de Janeiro: Gramma, 2010. pp. 79-99.

Indústria e Território no Brasil Contemporâneo. Rio de Janeiro: Garamond, 2007. $167 \mathrm{p}$.

(Org.). Petróleo, Royalties e Região. Rio de Janeiro: Garamond, 2003.

; SERRA, Rodrigo. Petróleo e Região no Brasil: o desafio da abundância. Rio de Janeiro: Garamond, 2007.

SANTOS, Angela Moulin S. Penalva; MARAFON, Glaucio J.; SANT'ANNA, Maria Josefina. Rio de Janeiro: um olhar socioespacial. Rio de Janeiro: Gramma, 2010. $392 p$.

SEBRAE. Ocupação e empreendedorismo nas regiões do ERJ, com base no Censo 2010, do IBGE. Observatório das micro e pequenas empresas no ERJ: Rio de Janeiro, 2012.

SILVA, Mauro Osório. O papel das instituições na trajetória econômico-social do Estado do Rio de Janeiro. Rio de Janeiro, 2013. mimeo. 25p.

SILVA, Roberto Rosendo. O sistema de inovação do Estado do Rio de Janeiro: impactos da industrial petrolífera. Tese de Doutorado. Niterói, R.J.: Faculdade de Economia, Universidade Federal Fluminense, 2008.

SILVA, Robson Santos. Indústria e desenvolvimento regional no Rio de Janeiro, 19902008. Rio de Janeiro: FGV, 2012. 258p.

VAINER, Carlos B. Planejamento territorial e projeto nacional: os desafios da fragmentação. Revista Brasileira de Estudos Urbanos e Regionais, v. 9, n. 1. Salvador, Bahia: Associação Nacional de Pós-Graduação e Pesquisa em Planejamento Urbano e Regional, 2007. 